\title{
Coupled Thermomechanical Micromechanics Modeling of the Influence of Thermally Grown Oxide Layer in an Environmental Barrier Coating System
}

\author{
Trenton M. Ricks, \\ Steven M. Arnold, \\ and \\ Bryan J. Harder
}

Materials and Structures Division

NASA Glenn Research Center

Cleveland, $\mathrm{OH}$ 


\section{Introduction}

Aircraft engine efficiency can be significantly improved with advanced materials

- Higher temperature materials require less cooling air

- Lower density materials can lead to lower weight of components

Ceramic Matrix Composites (CMCs) offer a significant improvement over metals

- CMCs with $2400^{\circ} \mathrm{F}$ capability began flying in commercial aircraft engines in 2016

- This is $\sim 300^{\circ} \mathrm{F}$ higher temperature capability than metals, at $1 / 3$ of the density

- Require Environmental Barrier Coatings (EBCs) for operation

NASA is developing a material system with $2700^{\circ} \mathrm{F}$ capability

- This technology would reduce aircraft fuel burn by approximately an additional $6 \%$, as well as lowering emissions 


\section{CMCs and EBCs}

\section{Ceramic Matrix Composites (CMCs)}

- High temperature material of small diameter silicon carbide (SiC) fibers surrounded by a bulk SiC matrix

- The matrix provides rigidity and overall shape

- Fibers allow for crack deflection/toughness

- React with water vapor in combustion environments

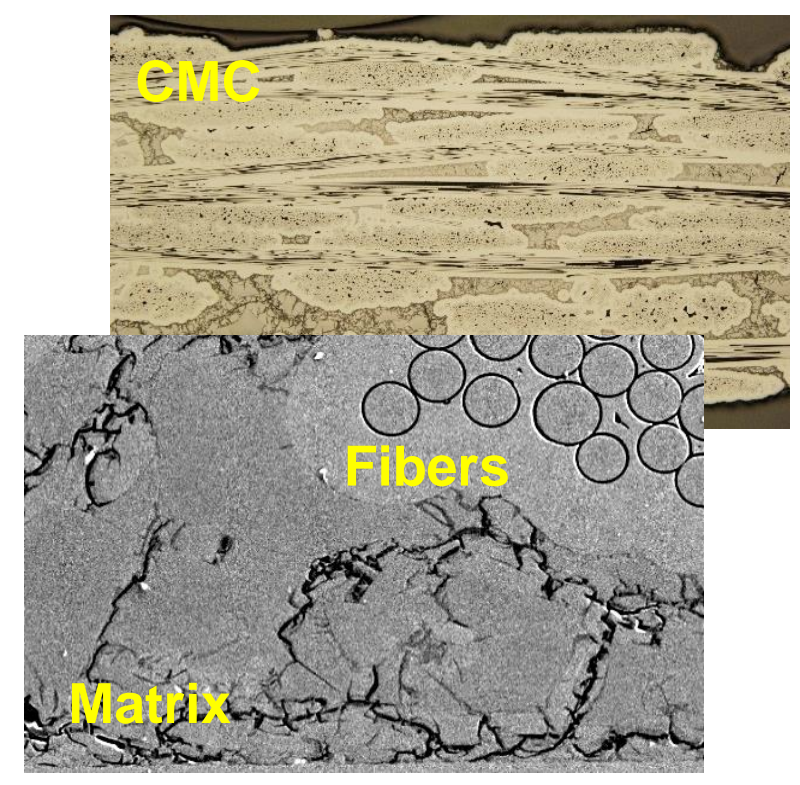

\section{Environmental Barrier Coatings (EBCs)}

- Needed to protect CMCs from engine environment

- Can be single layer or multilayer

- Typically oxides or silicates

- Applied using a variety of methods

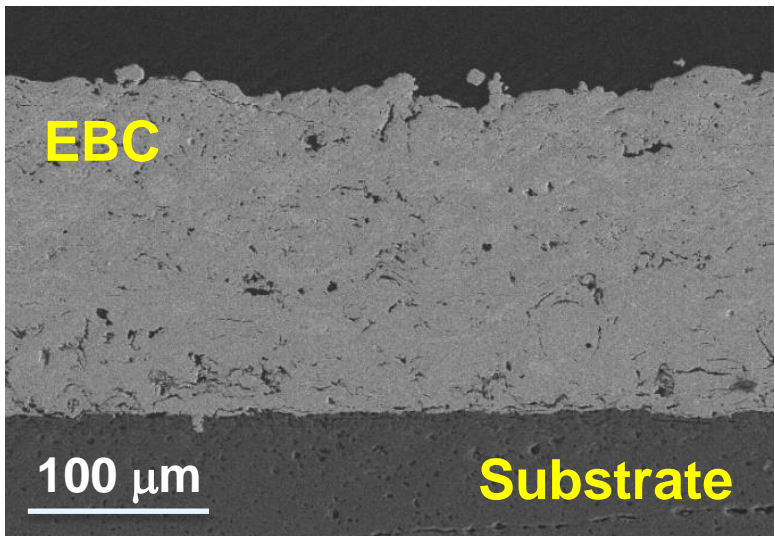




\section{Environmental Barrier Coating (EBC) Systems}

- Although durable, EBC systems must survive for 10,000+ hours

- Lifetime of EBC/CMC systems is limited by the formation of a thermally grown oxide (TGO)

- $\mathrm{SiO}_{2} \mathrm{TGO}$ can grow on either silicon bond coat or SiC substrate

- Observed failures

- Vertical Cracks

- Horizontal Cracks (Delamination)

- Critical thickness for failure is roughly 20-30 microns

- Can vary due to exposure temperature, microstructure, etc

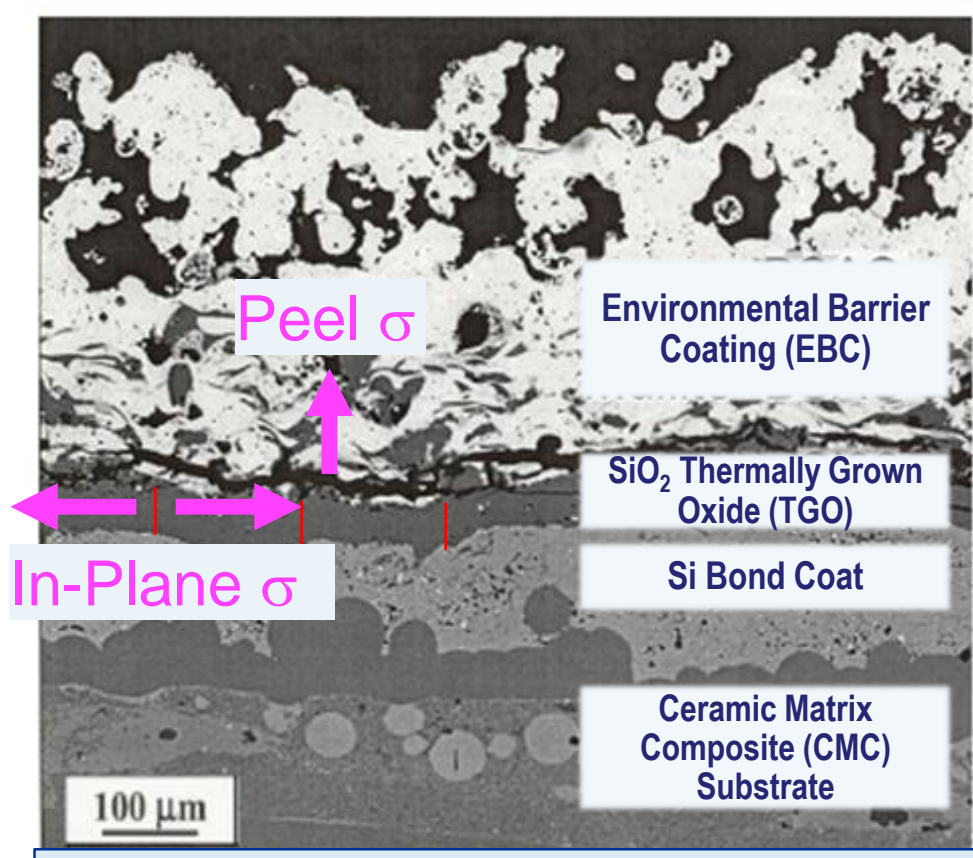

Environmental Barrier Coating system after $15,144 \mathrm{~h}$ test

Ultimate Goal: Predict the durability of EBC/CMC system when subjected to harsh environments 


\section{Current Study Objective}

- Perform a sensitivity study to examine the influence of uniformly and nonuniformly grown oxide layers on the associated driving forces leading to mechanical failure (spallation) of EBC layer when subjected to isothermal loading

- Ignore residual stresses due to processing

- Ignore cyclic loading effects

- Qualitative not quantitative study

- Wanting to understand influence factors on driving forces away from the free edge

- What influences critical TGO thickness

- Examined 3 layer and 4 layer system
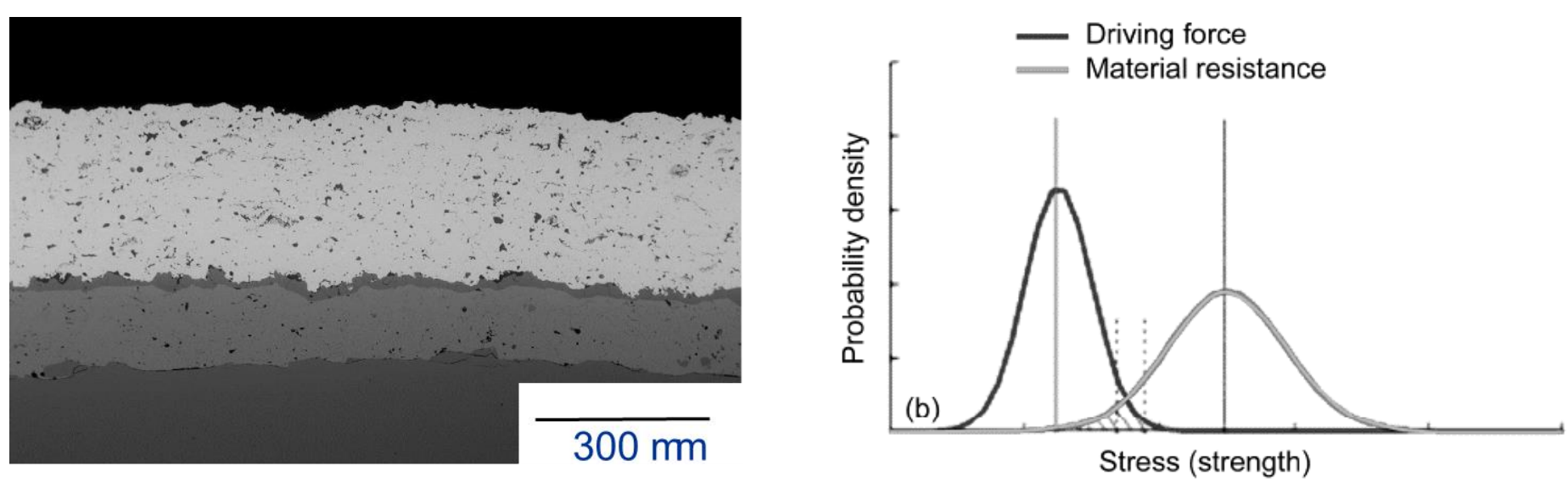


\section{HOTFGM: High Order Theory for Functionally Graded Materials}

HOTFGM offers a comprehensive approach towards analyzing/designing the response of components with various microstructural details.

Capabilities include:

1. Combined thermal and mechanical analysis

2. Time-independent and time-dependent material behavior

3. Free-edge effects

4. Microstructure variability

5. Internal boundary cells (e.g. that can be used to represent internal cooling passages)

6. User-friendly graphical user interface

a. define material distribution with a variety of techniques for distributing materials

b. specify general thermal and mechanica boundary conditions,

c. view time dependent temperature, stress, and strain results.

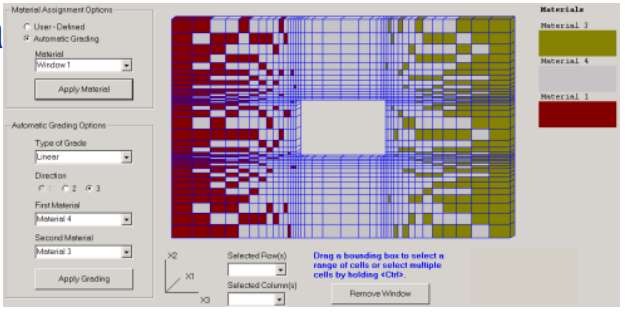

*It has been commercialized by HyperSizer: Ncell

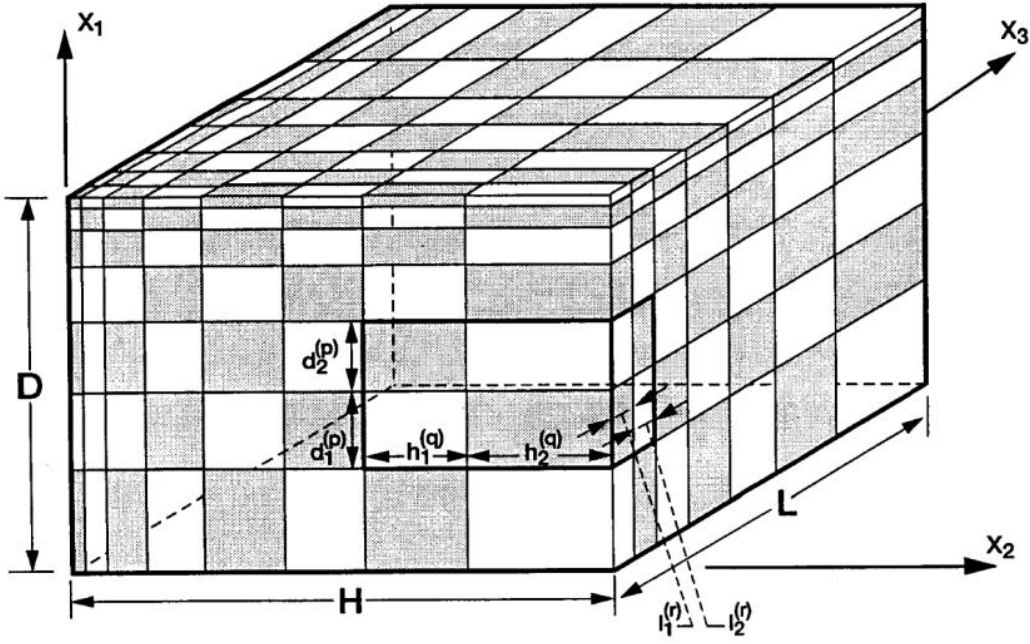

$\underline{2}^{\text {nd }}$ order Taylor Series Expansion of displacement

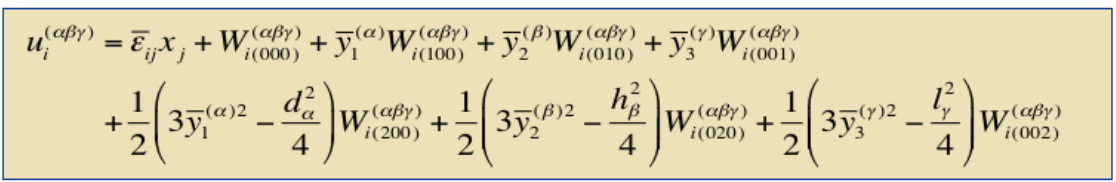

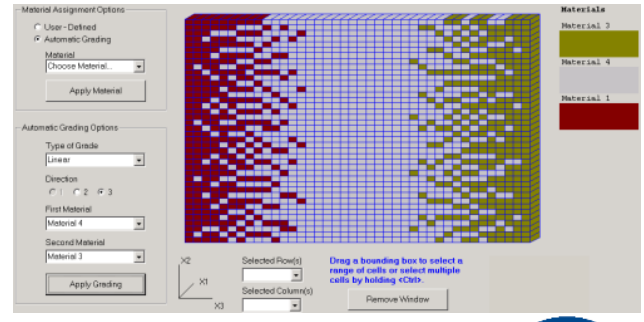




\section{Constituents' Material Parameters}

- Assume isotropic thermoelastic properties

\begin{tabular}{|c|c|c|c|c|c|c|}
\hline Material & $\begin{array}{c}\text { Thickness } \\
(\mathrm{mm})\end{array}$ & $\begin{array}{c}\text { Modulus } \\
(\mathrm{GPa})\end{array}$ & $\begin{array}{c}\text { Poisson } \\
\text { Ratio }\end{array}$ & $\begin{array}{c}\mathrm{CTE} \\
\left(\mathrm{x}^{-6} \mathrm{~K}^{-1}\right)\end{array}$ & $\begin{array}{c}\text { Conductivity } \\
(\mathrm{W} / \mathrm{m}-\mathrm{K})\end{array}$ & Strength (MPa) \\
\hline $\begin{array}{c}\mathrm{Yb}_{2} \mathrm{Si}_{2} \mathrm{O}_{7} \\
(\mathrm{EBC})\end{array}$ & 0.175 & 200 & 0.27 & 4.5 & 1.25 & $45-65$ \\
\hline $\mathrm{SiO}_{2}(\mathrm{TGO})$ & $\begin{array}{c}0.001 \\
0.002 \\
0.004\end{array}$ & 35 & 0.17 & 10 & 1.4 & $45-75$ \\
\hline $\begin{array}{c}0.008 \\
\mathrm{Si}\end{array}$ & 0.016 & 97 & 0.21 & 4.5 & 14.23 & $40-55$ \\
\hline $\begin{array}{c}\text { (Bond Coat) } \\
\text { Hexoloy SiC } \\
\text { (Substrate) }\end{array}$ & $3.000^{*}$ & 400 & 0.17 & 5.25 & 30 & $380-550$ \\
\hline
\end{tabular}

* Initial thickness assuming no TGO, bond coat 


\section{Idealization Of Three Layer System, With Geometry And Applied Thermal And Mechanical Boundary Conditions}

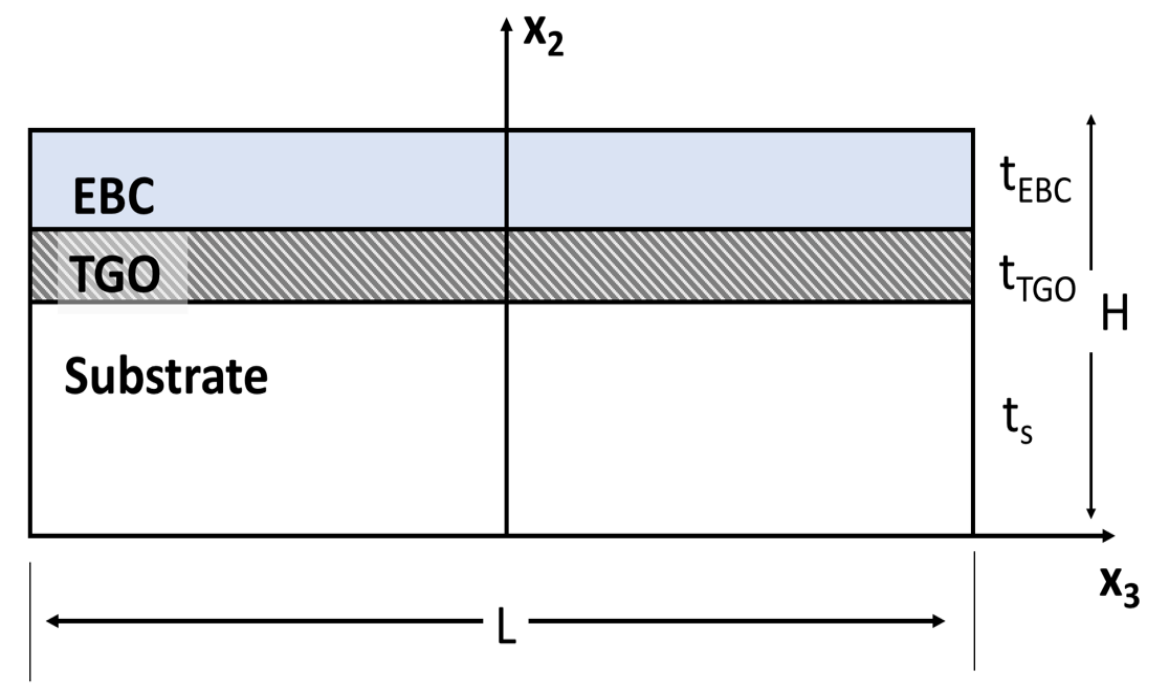

Boundary Conditions

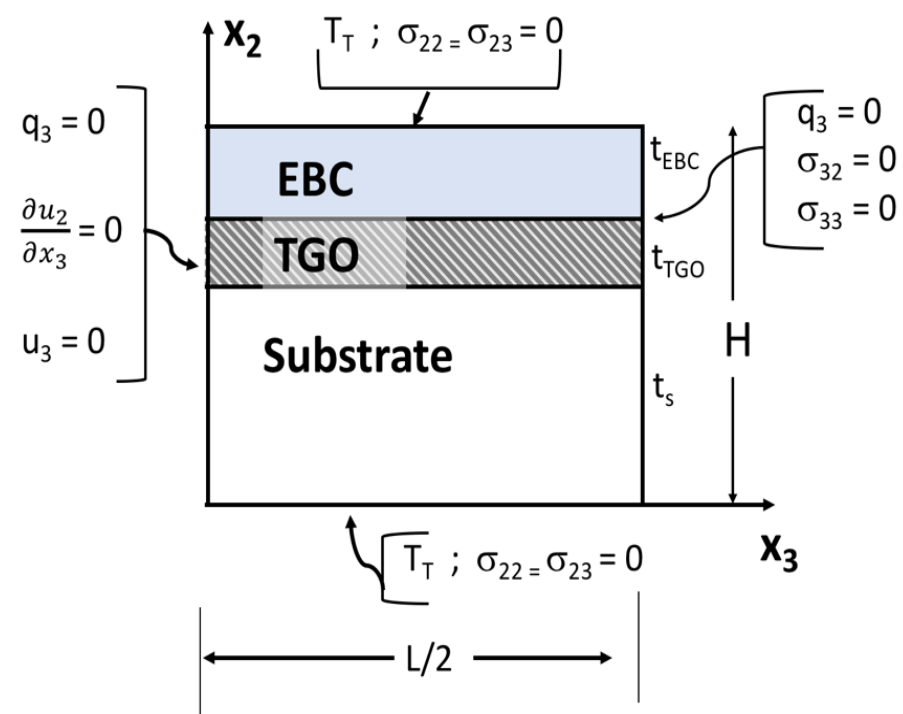

- Global loading is cool-down from $1482 \mathrm{C}$ to $38.7 \mathrm{C}\left(2700{ }^{\circ} \mathrm{F}\right.$ to $\left.102^{\circ} \mathrm{F}\right)$

- Applied in one step since material assumed to be linearly elastic

- Stress state is generated due to geometry and mismatch in constituent material properties 


\section{Results: Uniform Layers}

\section{Baseline: Two Layer (EBC/CMC)}

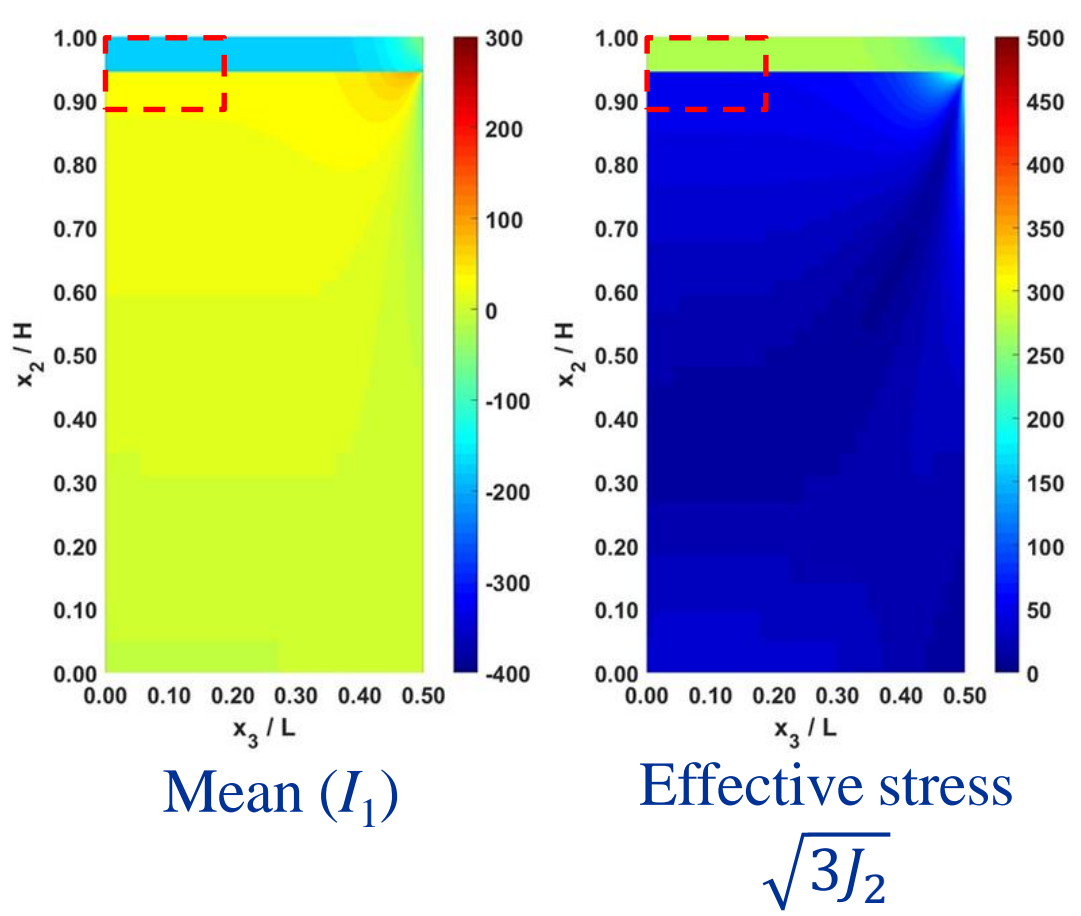

Baseline: Three Layer (EBC/TGO/CMC)

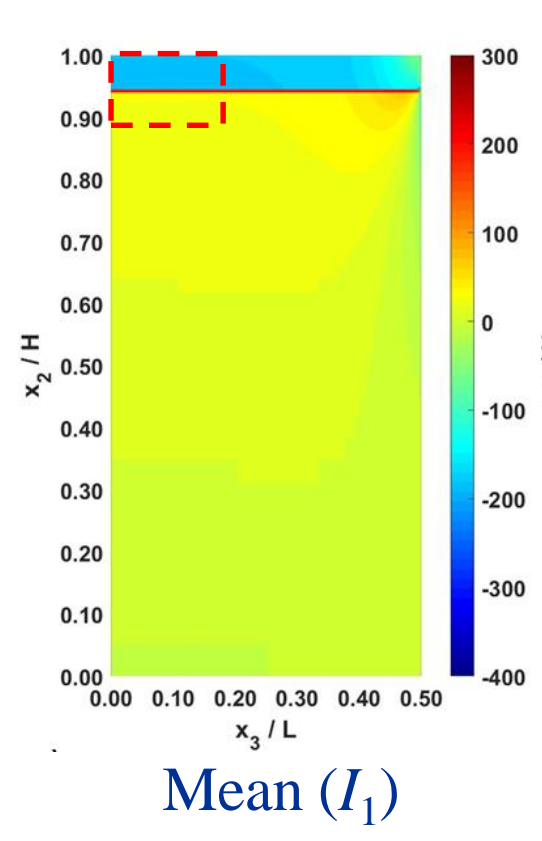

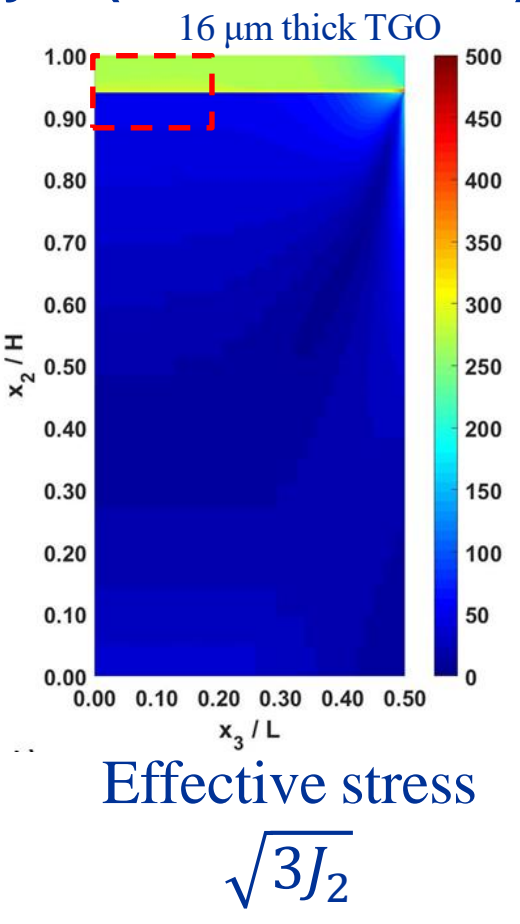

- $\quad$ Stress state uniform away from the free edge and throughout the TGO thickness 


\section{Results: Uniform Layers}

Thin $1 \mu \mathrm{m}$ TGO Layer
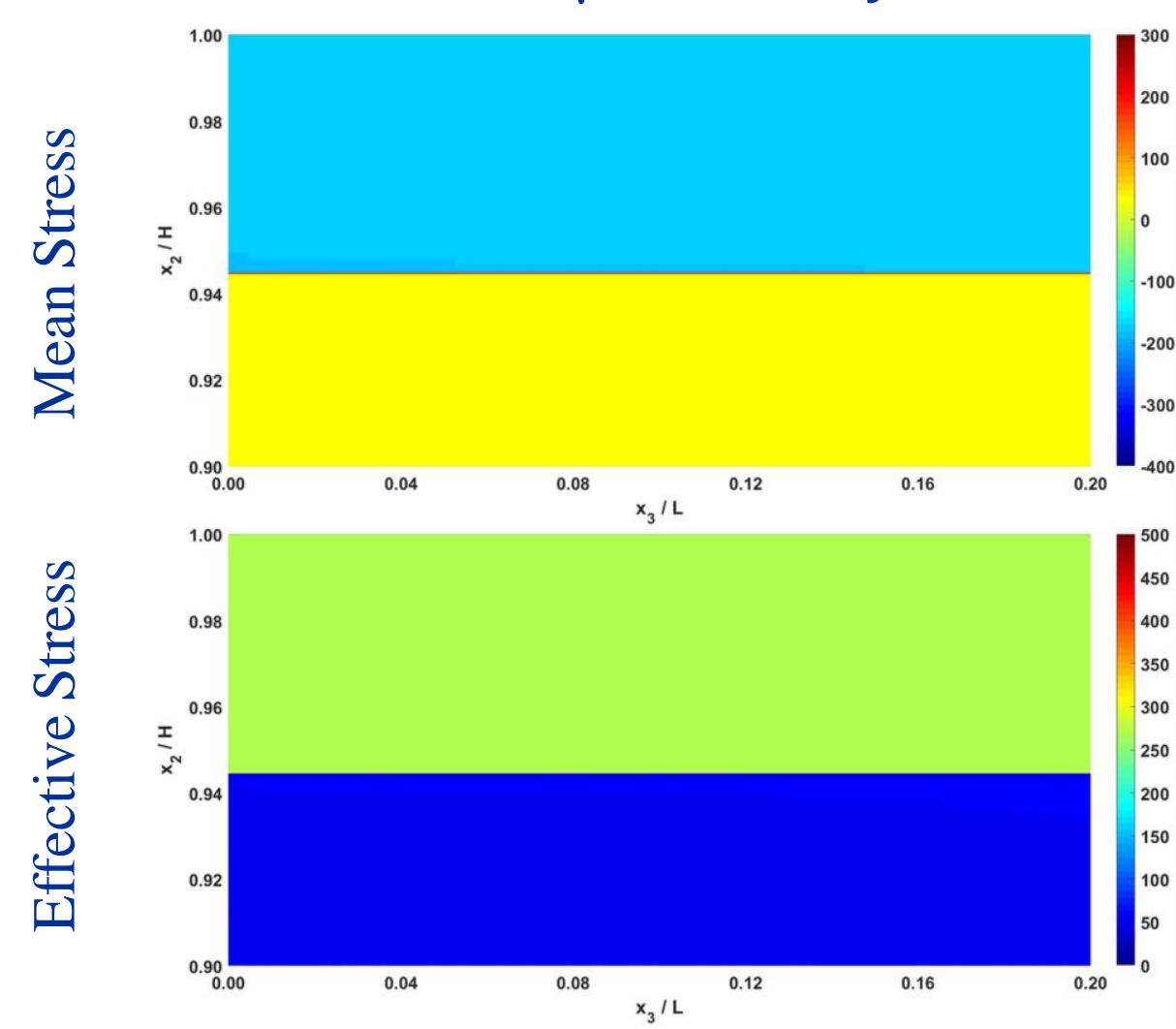

Thick $16 \mu \mathrm{m}$ TGO Layer
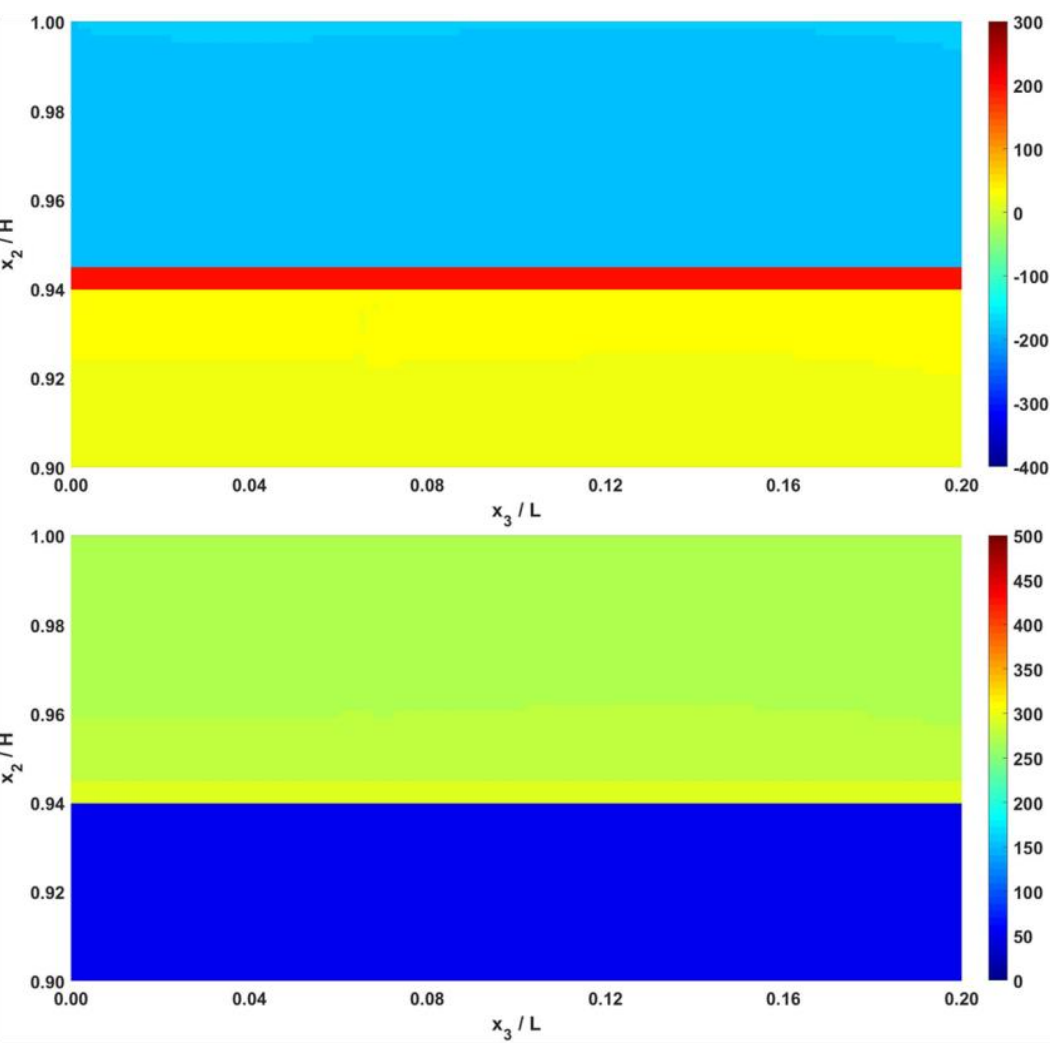

- TGO thickness has no significant $(<1 \%)$ effect on the resulting stress state in the system 


\section{Results: Uniform Layers}

In-plane normal stress $\left(\sigma_{11}\right)$ along the symmetry plane $\left(\mathrm{x}_{2}=0\right)$

near the substrate/TGO and TGO/EBC interfaces

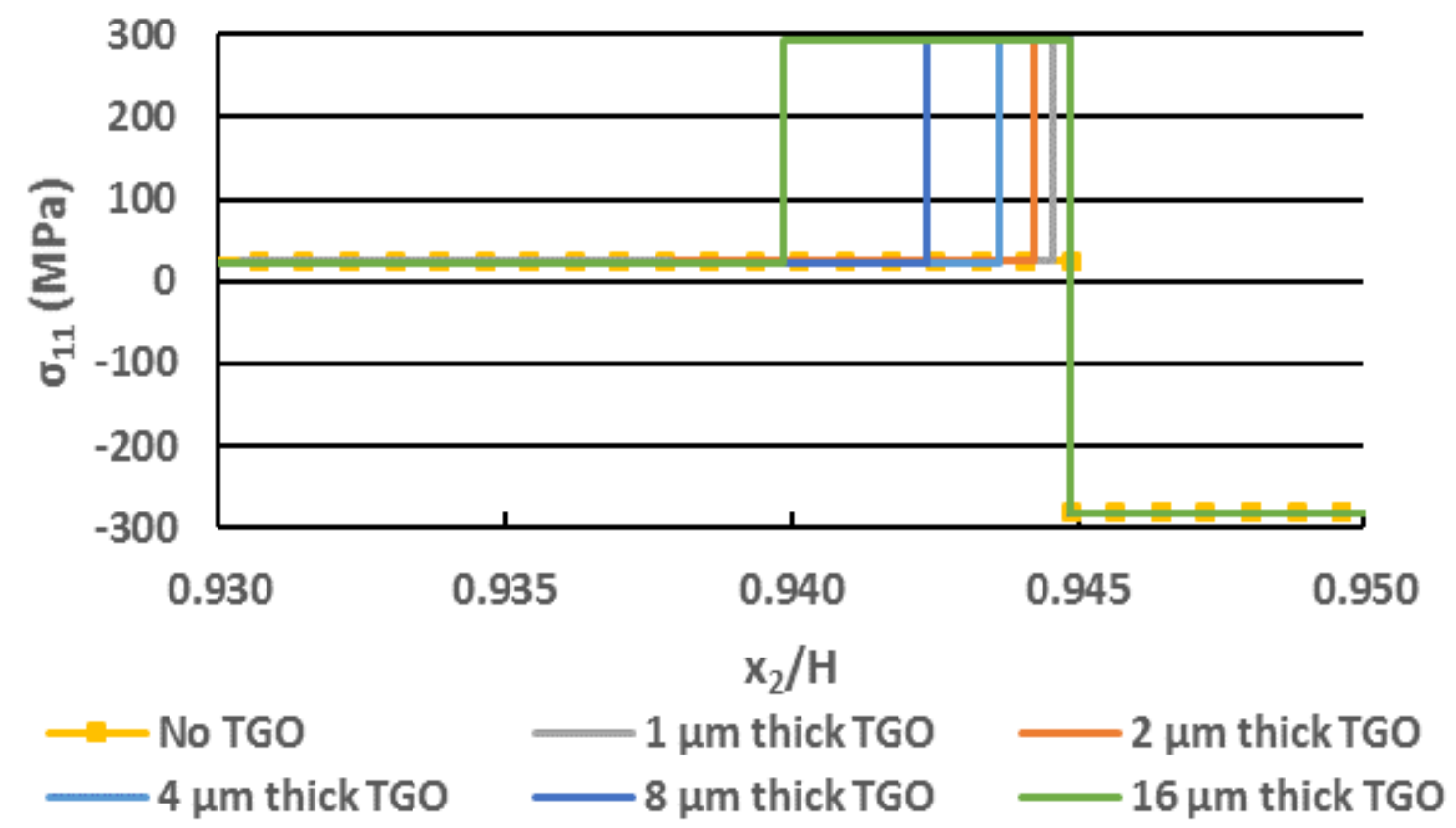

- Magnitude of the tensile stress within the TGO remains nearly identical for all thickness (no criteria for calculating critical TGO thickness)

- Volume of TGO impacted by tensile stress however increases with thickness - thus suggesting that the resistance will most likely be reduced

- In-plane stresses are only nonzero component - explains only vertical cracking 


\section{Nonuniform Layer Idealization}

\section{Schematic showing discontinuous TGO layer geometry}

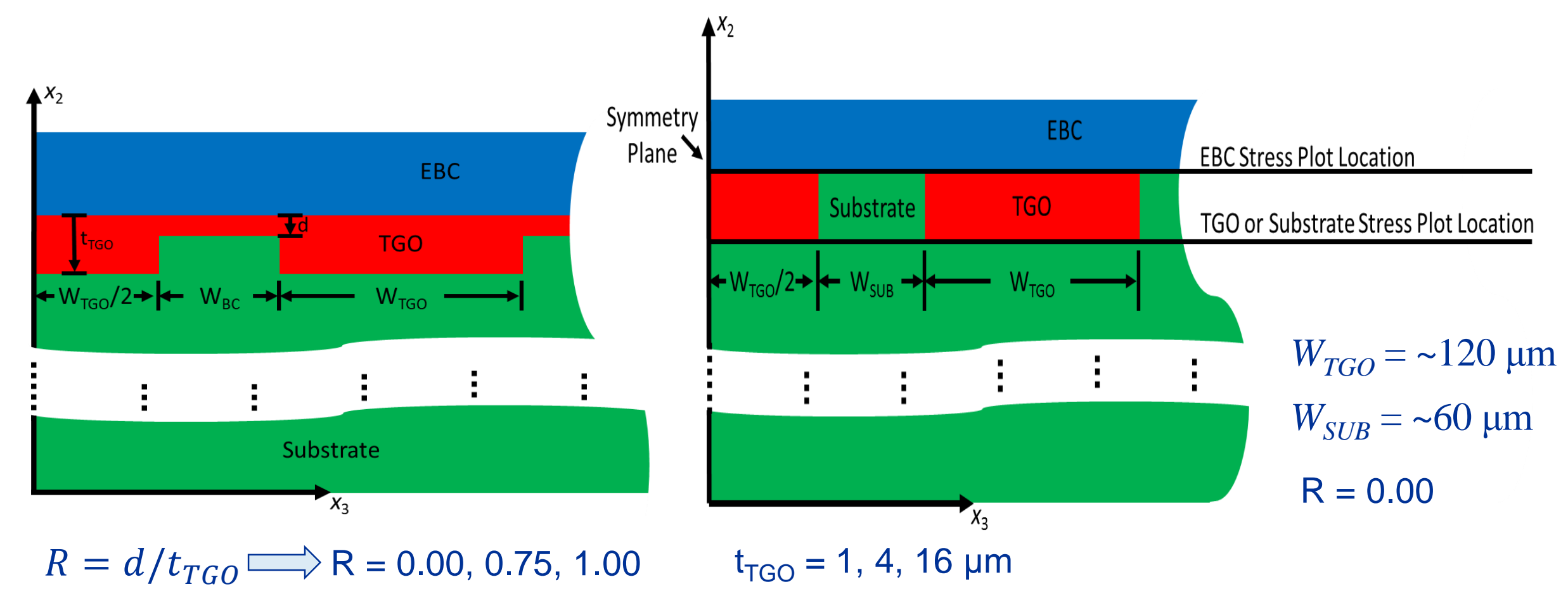

- $\quad$ EBC, TGO, and CMC substrate involving only the first $\sim 550 \mu \mathrm{m}$ out of $5000 \mu \mathrm{m}(L / 2)$ in the $x_{3}$-direction

- Discontinuous TGO "islands" inserted between the substrate and EBC interface

- $\quad$ Severity of nonuniformity considered by adjusting $R$ factor

- $\quad$ Initial TGO island width was set to half its full width (symmetry boundary conditions) 


\section{Results: Nonuniform Layers}

Thin $1 \mu \mathrm{m}$ TGO Layer
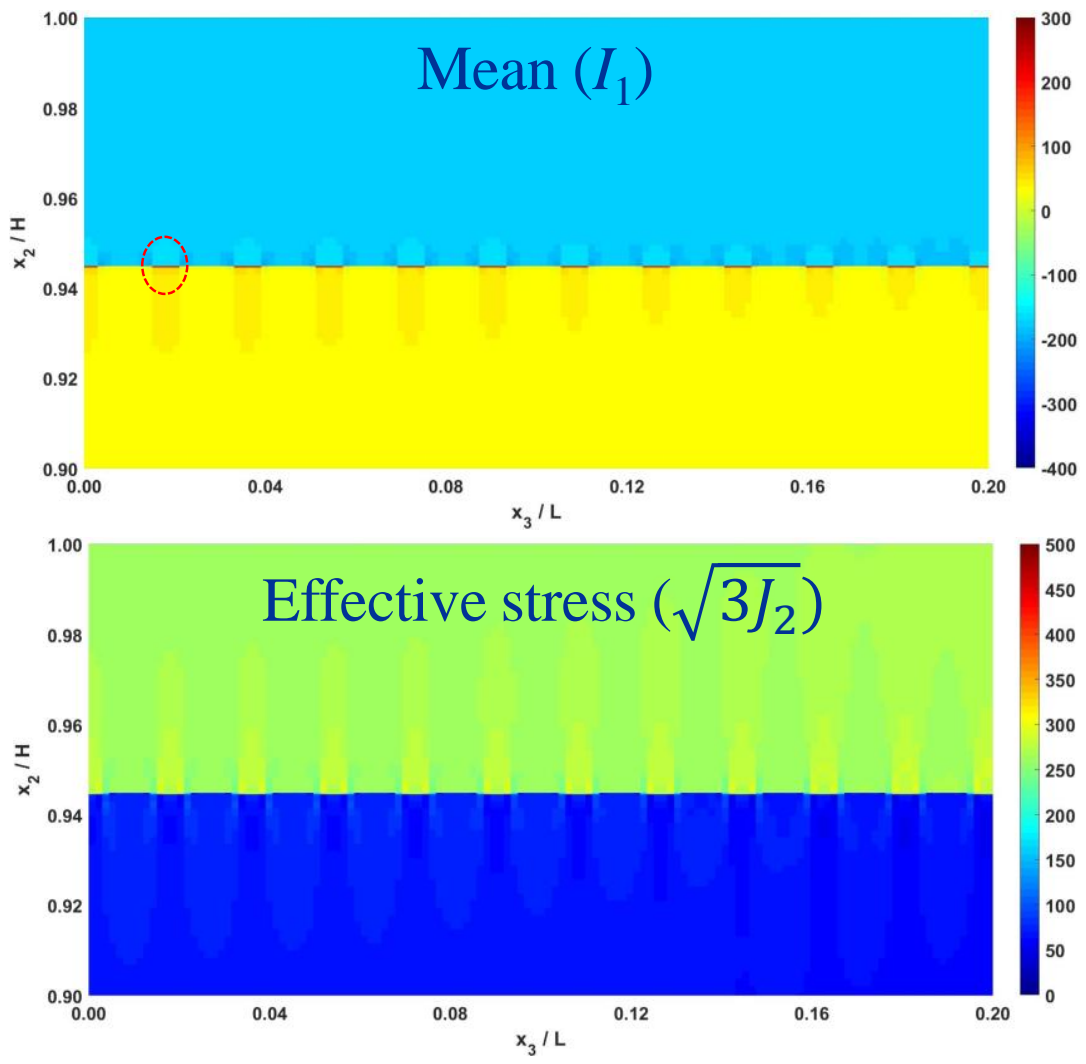

Thick $16 \mu \mathrm{m}$ TGO Layer
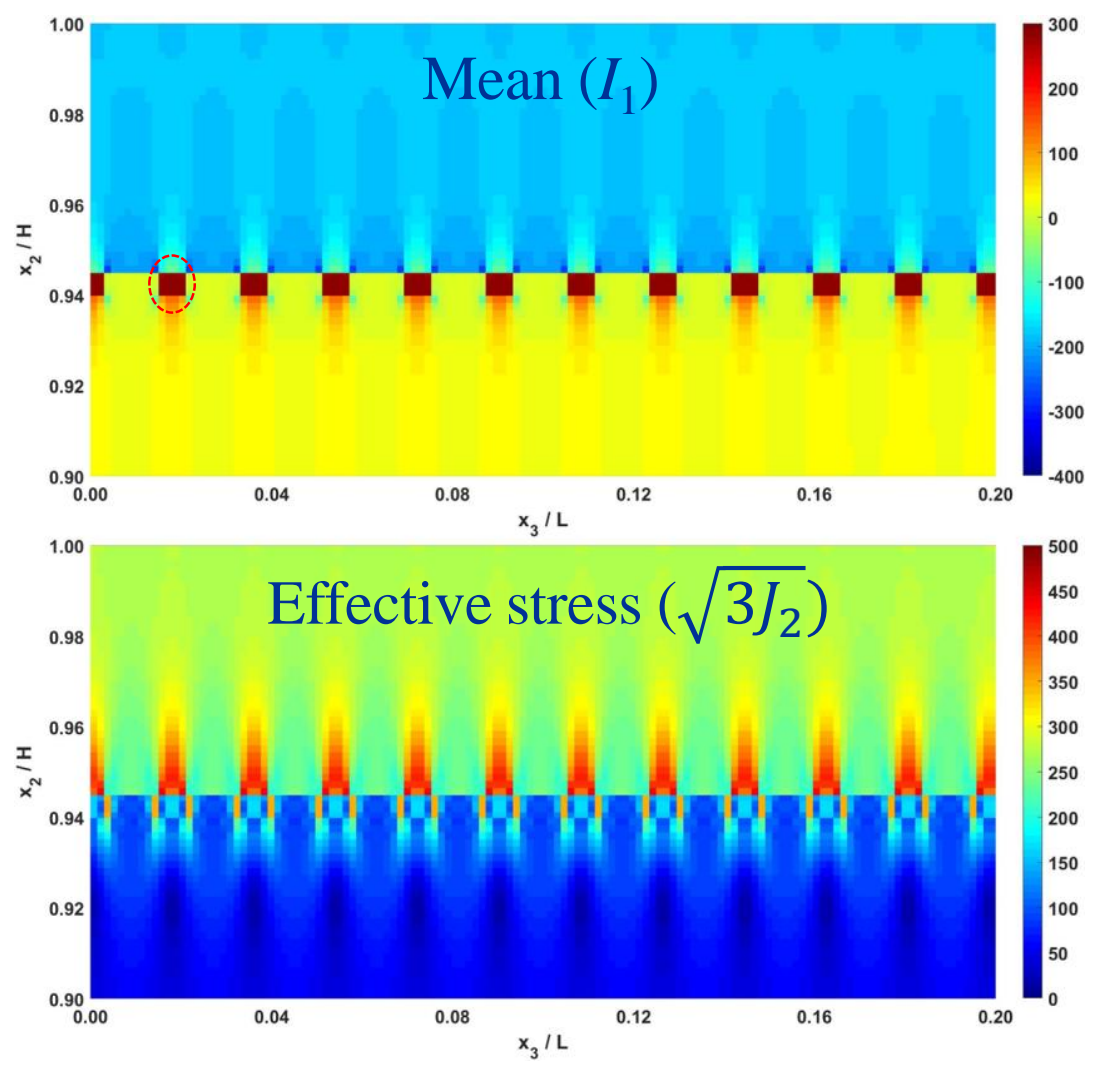

- Results are plotted away from free-edge

- Island edges introduce concentrations in both mean and effective stress

- As TGO thickness increases the magnitudes significantly increase 


\section{Results: Nonuniform Layers}

\section{Thin $1 \mu \mathrm{m}$ TGO Layer}

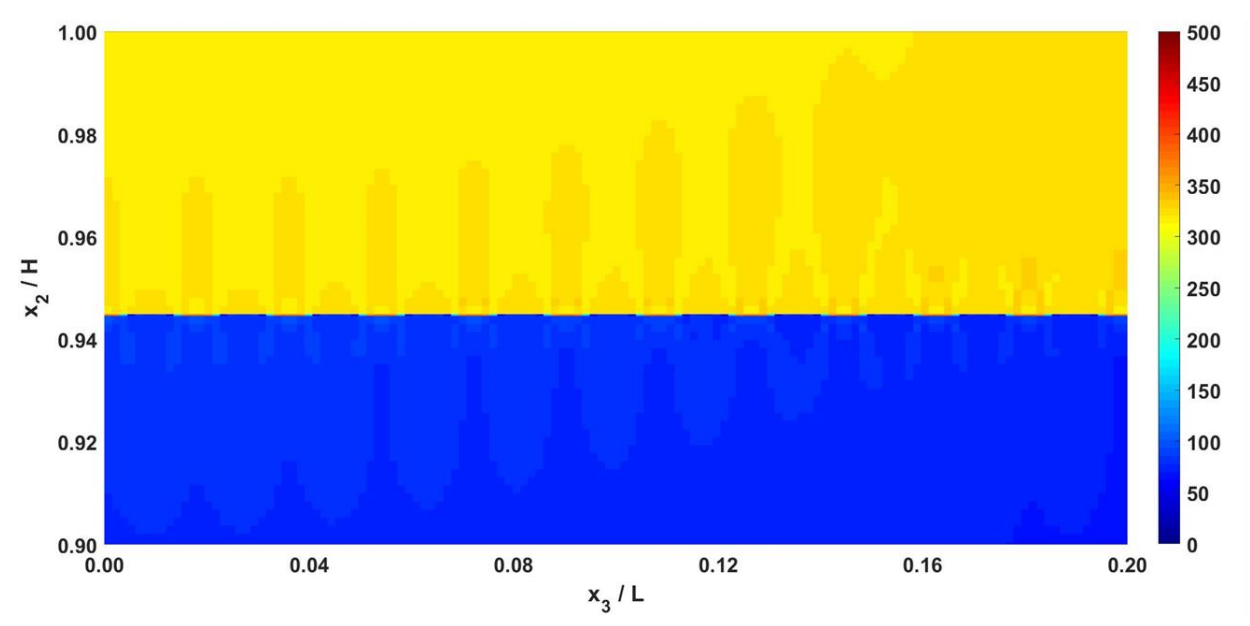

Thick $16 \mu \mathrm{m}$ TGO Layer

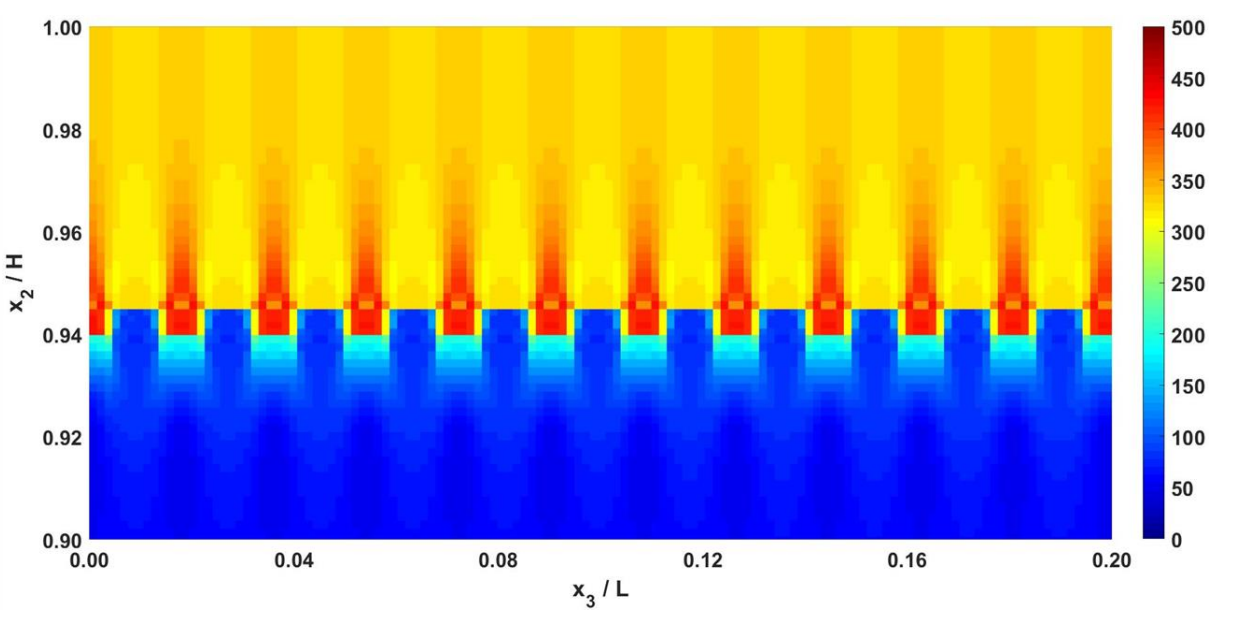

- Equivalent damage stress from Lemaitre and Chaboche, Mechanics of solid materials

- Calculated by assuming equivalence in energy between multiaxial and uniaxial states

$$
\sigma^{*}=\sigma_{e f f} \sqrt{\frac{2}{3}(1+v)+3(1-2 v)\left(\frac{\sigma_{H}}{\sigma_{e f f}}\right)^{2}}
$$

- Captures both mean and effective stress effects

- Increase in equivalent damage stress with increasing TGO thickness 


\section{Nonuniformity in TGO Provides Driving Forces Consistent With EBC Spallation}
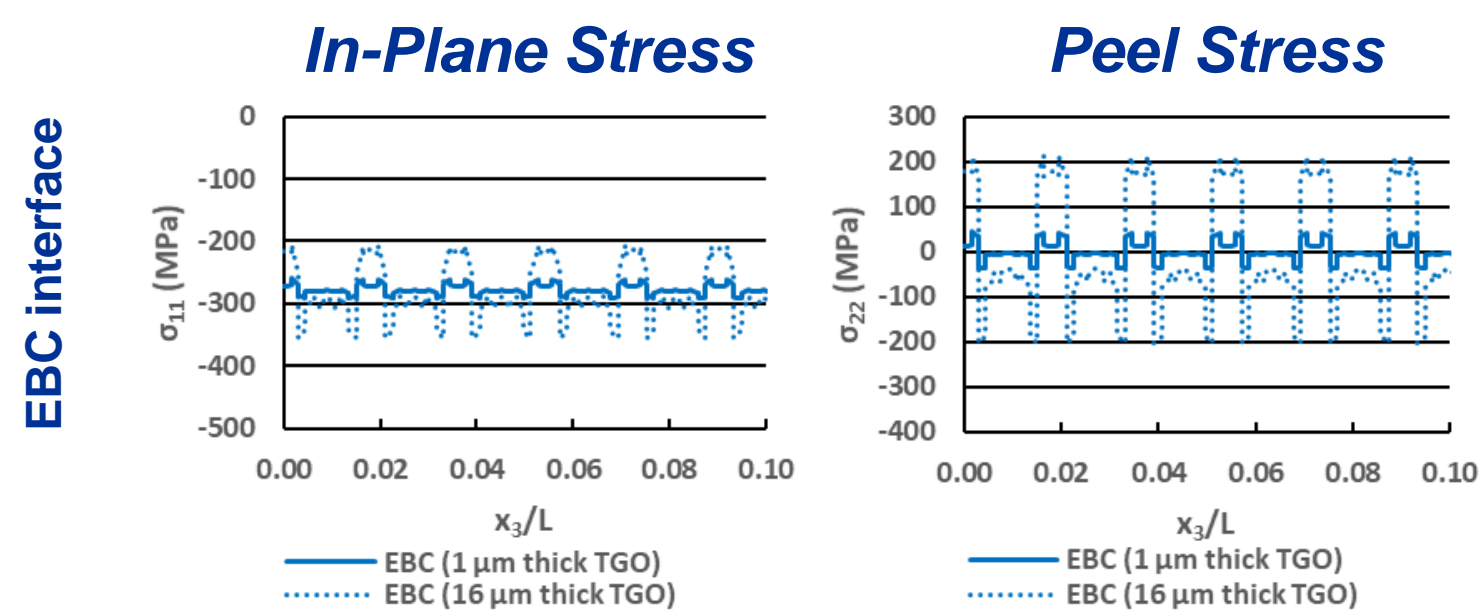

Shear Stress
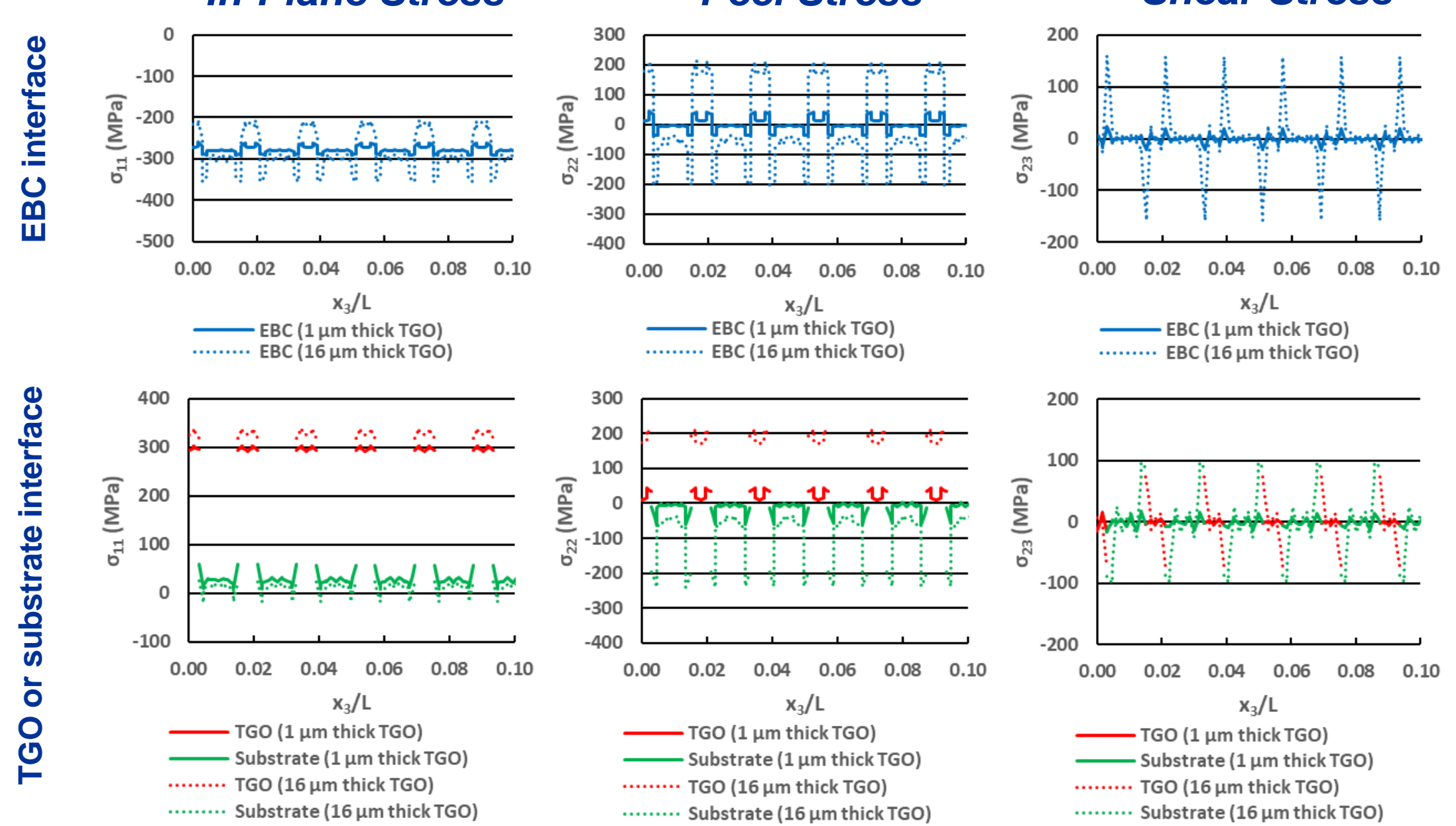

- High in-plane stress $\left(\sigma_{11}, \sigma_{33}\right)$ - suggests vertical cracking likely

- Tensile peel stress $\left(\sigma_{22}\right)$ - suggests potential EBC spallation in the vicinity of a TGO island 


\section{Influence of Severity of Non-uniformity}

$$
R=d / t_{T G O} \longrightarrow \text { Lower value = more severe nonuniformity }
$$

Max Stress vs. R factor

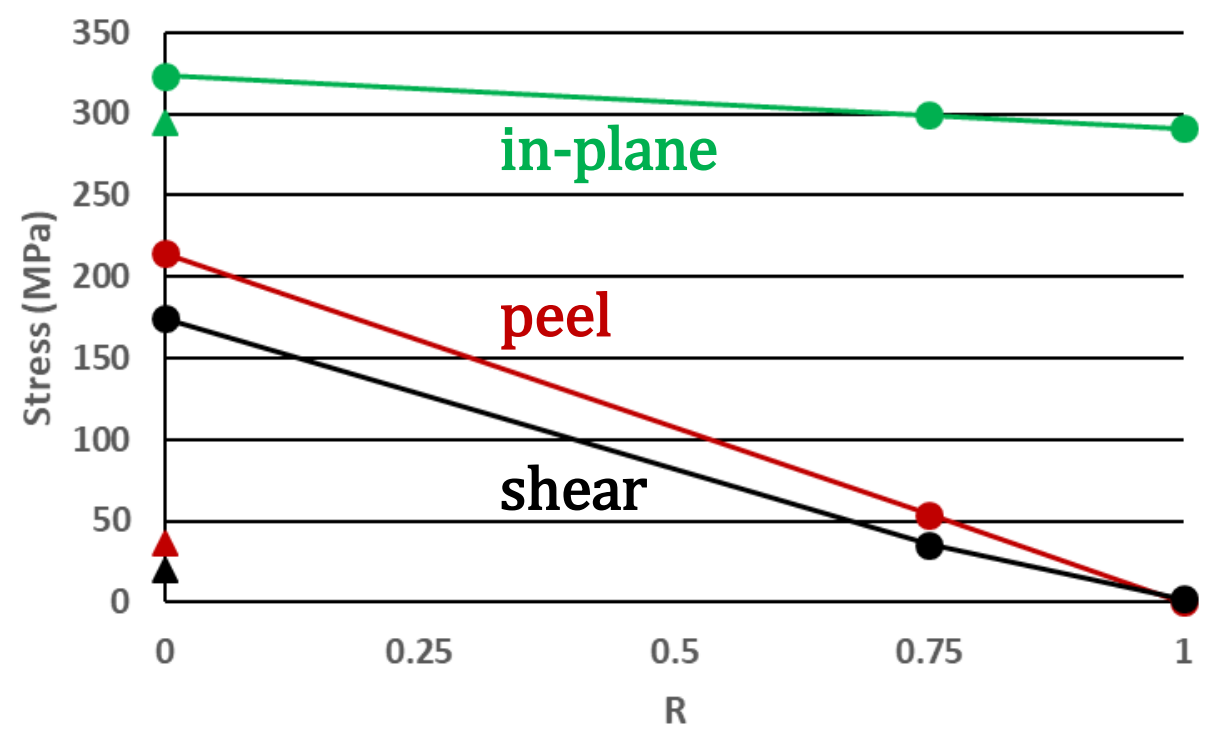

$-16 \mu \mathrm{m}$ TGO, $\sigma_{11 \mathrm{~T}}$ (in-plane)
$-16 \mu \mathrm{m}$ TGO, $\sigma_{22 \mathrm{~T}}$ (peel)
$-16 \mu \mathrm{m}$ TGO, $\sigma_{23}$ (shear)

$\Delta \quad 1 \mu \mathrm{m}$ TGO, $\sigma_{11 \mathrm{~T}}$ (in-plane)

$\Delta \quad 1 \mu \mathrm{m}$ TGO, $\sigma_{22 \mathrm{~T}}$ (peel)

$\Delta \quad 1 \mu \mathrm{m}$ TGO, $\sigma_{23}$ (shear)

- As R increases, stresses decrease

- reducing severity of nonuniformity = greater resistance to spallation

- Significant decrease in peel/shear stresses
Equivalent Damage Stress

$16 \mu \mathrm{m}$ TGO Layer, $\mathbf{R}=0.00$

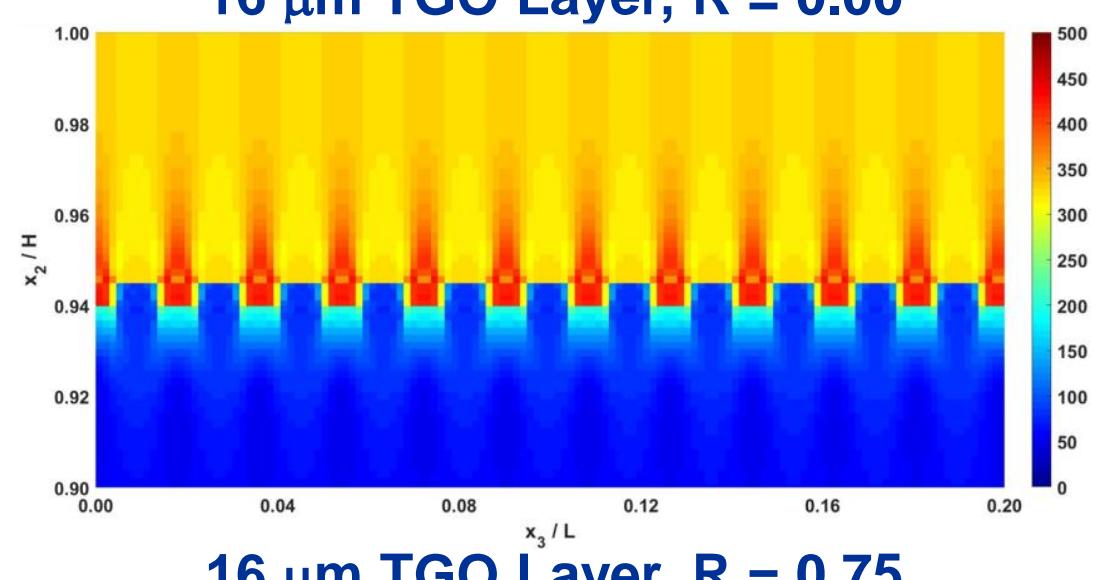

$16 \mu \mathrm{m}$ TGO Layer, $R=0.75$

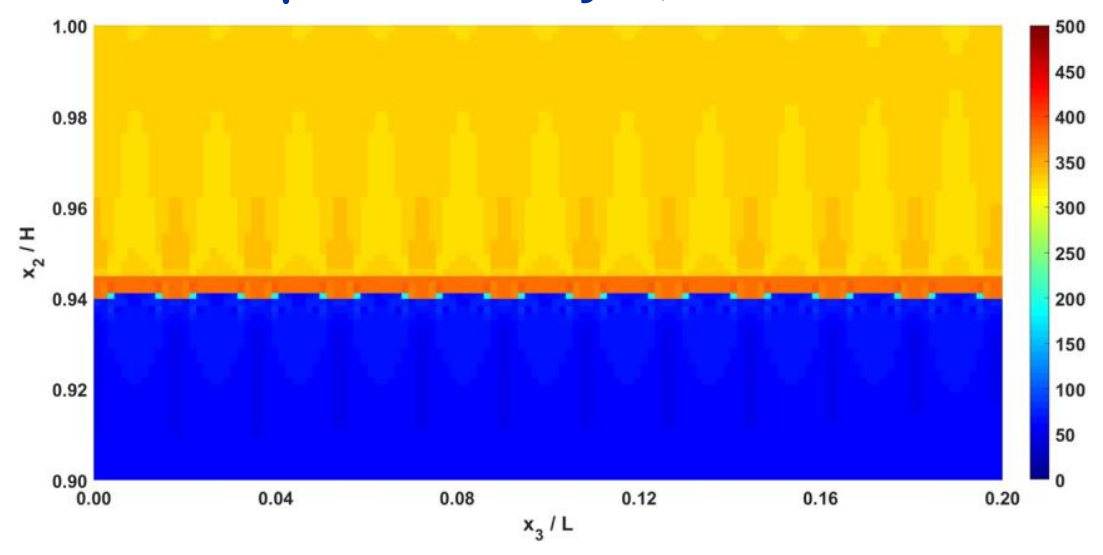




\section{Nonuniform Idealization - 4 Layer System}

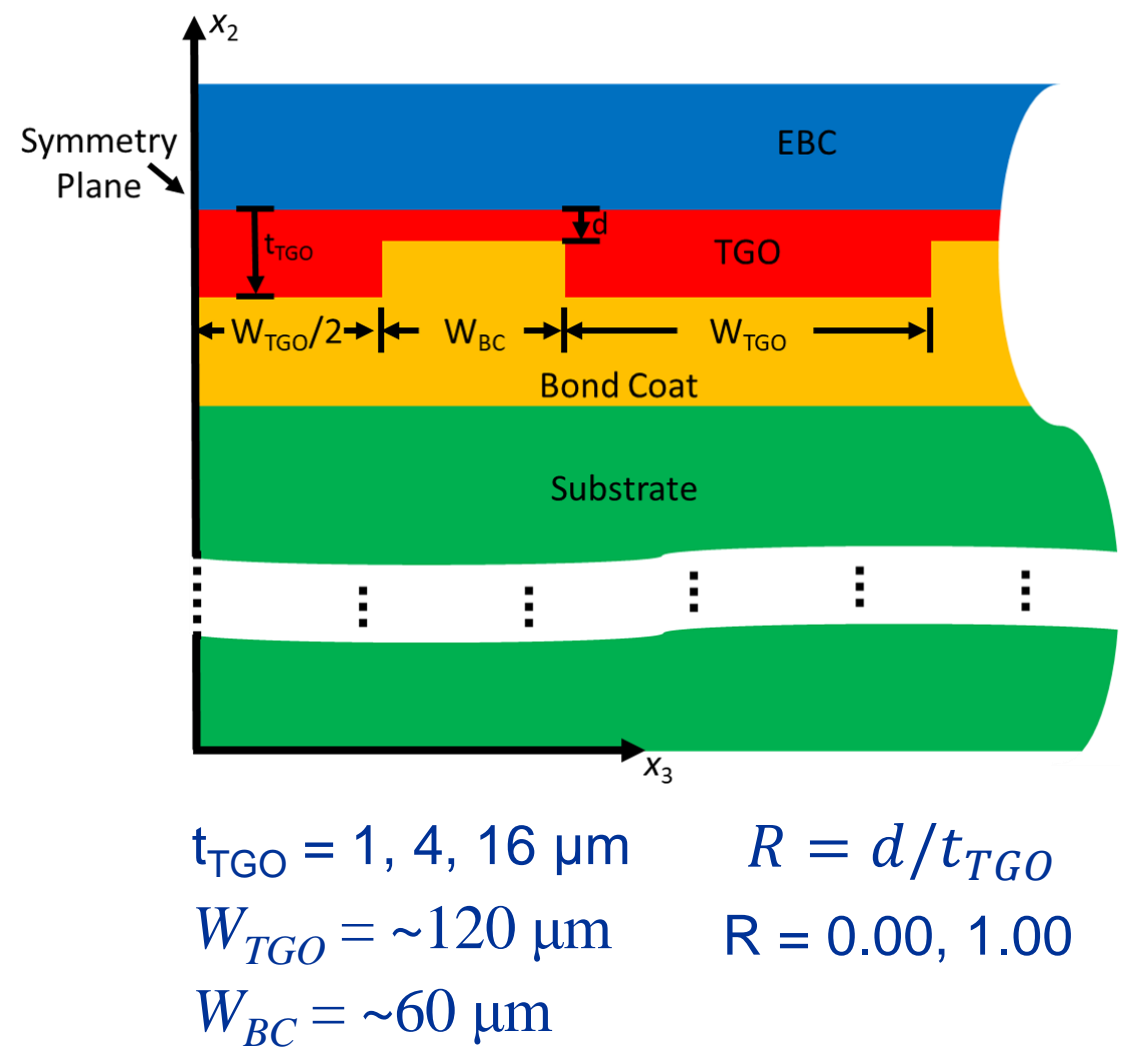

- Discontinuous TGO "islands" inserted between the substrate and EBC interface - Severity of nonuniformity considered by adjusting $R$ factor 


\section{Uniform TGO - 4 Layer System}

In-plane normal stress $\left(\sigma_{11}\right)$ along the symmetry plane $\left(x_{2}=0\right)$ near the substrate/bond coat, bond coat/TGO, and TGO/EBC interfaces

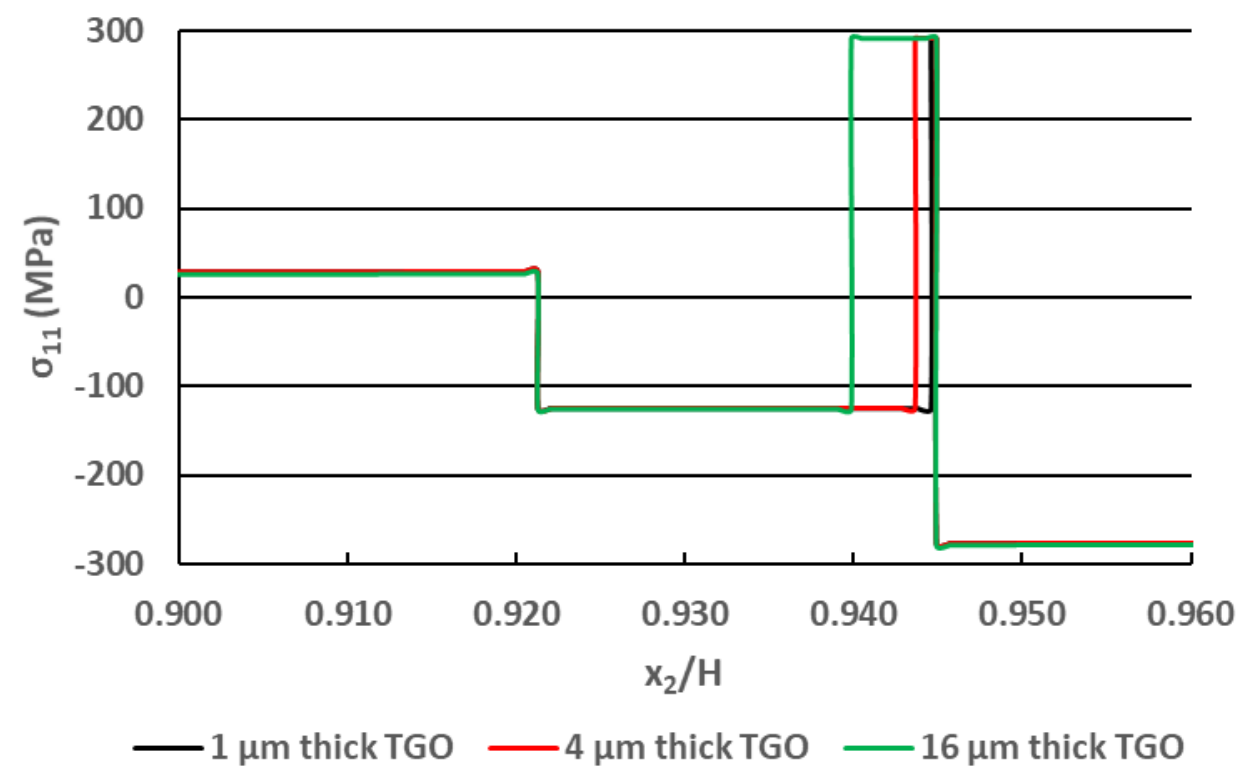

- Stress state insensitive to TGO thickness - similar to 3 layer system results

- Suggest no cracking in Si-bond coat due to compressive stress state 
Presence of Si Bond Coat Reduces Equivalent Damage Stress

Equivalent Damage Stress - $16 \mu \mathrm{m}$ TGO Layer, R = 0.00

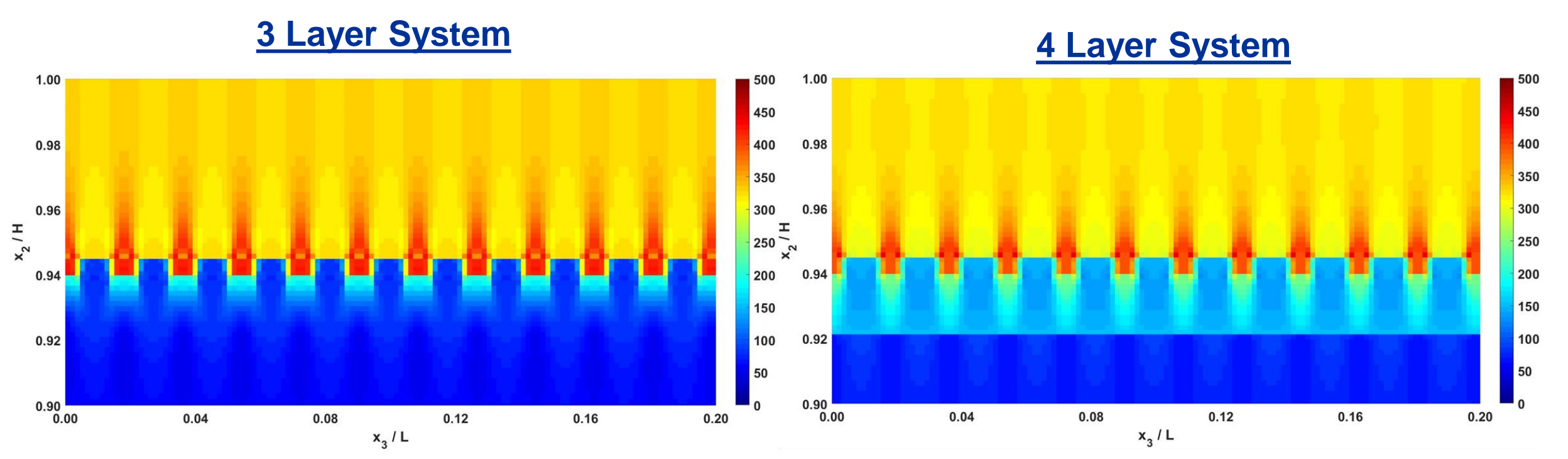

- Lower stress in TGO for 4 layer system 


\section{Presence of Si Bond Coat Reduces Driving Forces}
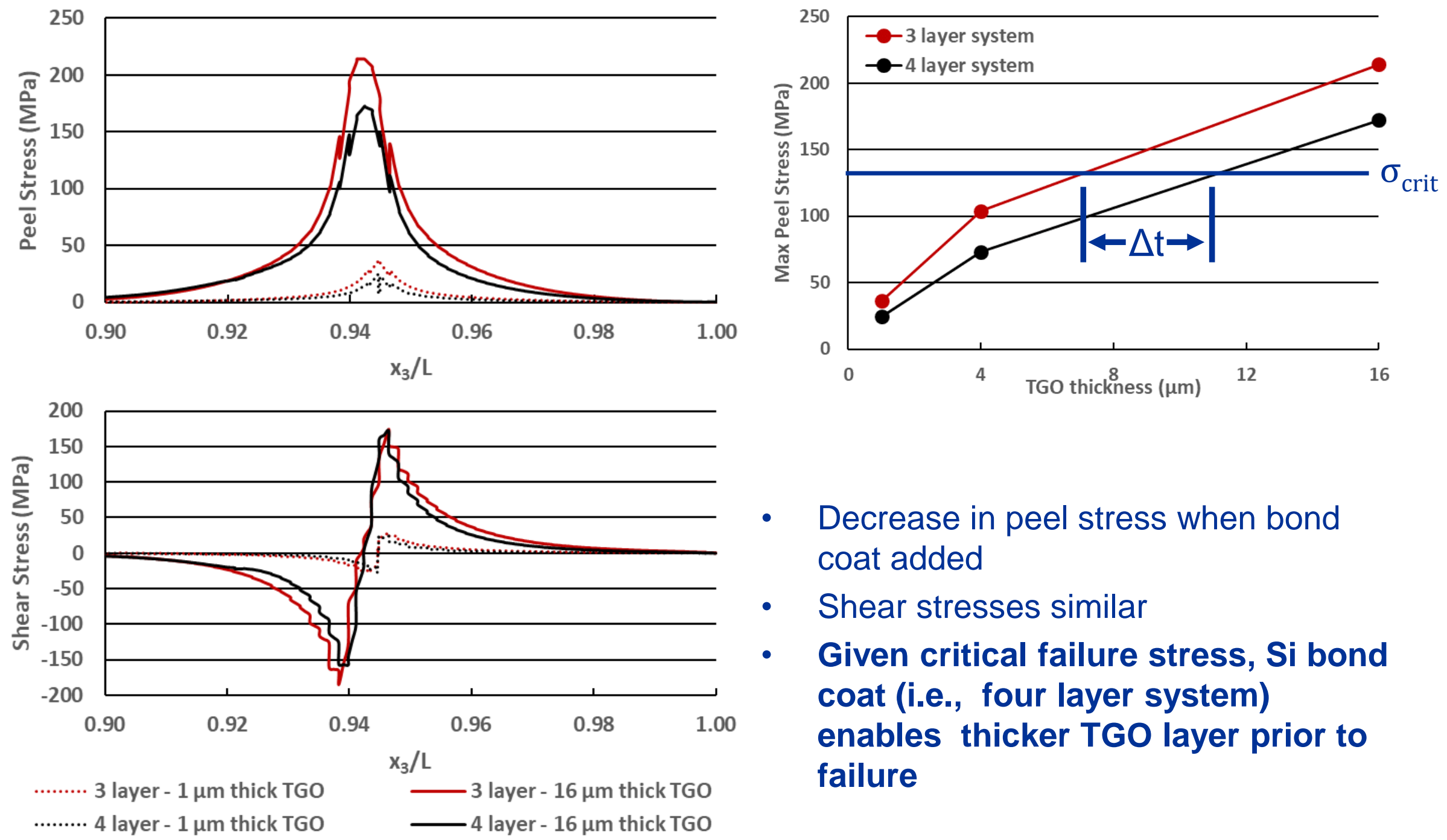

- Decrease in peel stress when bond coat added

- Shear stresses similar

- Given critical failure stress, Si bond coat (i.e., four layer system) enables thicker TGO layer prior to failure 


\section{Conclusions}

- HOTFGM tool enables efficient study of microstructural features (e.g., volume fraction, geometry, constituent phases, etc.) on overall composite response. Uniform TGO layers

- Stress state is constant away from free-edge.

- TGO thickness had a negligible effect on the magnitude of the stress state.

- To determine critical TGO thickness, change in material resistance must be included.

Nonuniform TGO layers

- Significant peel and shear stresses were predicted to occur in both the TGO and EBC near these nonuniformities.

- Magnitude of these components influenced based on thickness of TGO and severity of non-uniformity.

- These stresses could explain the onset and evolution of TGO damage and ultimately EBC spallation when a critical TGO thickness is reached.

- The idealized model considered in this study represents a first step at understanding the influence of TGO geometric nonuniformity on the stress state in a CMC/EBC system.

\section{Future Work}

material behavior (anisotropic, creep, damage, TGO evolution) thermomechanical cycling 


\section{Thank You For Your Attention}

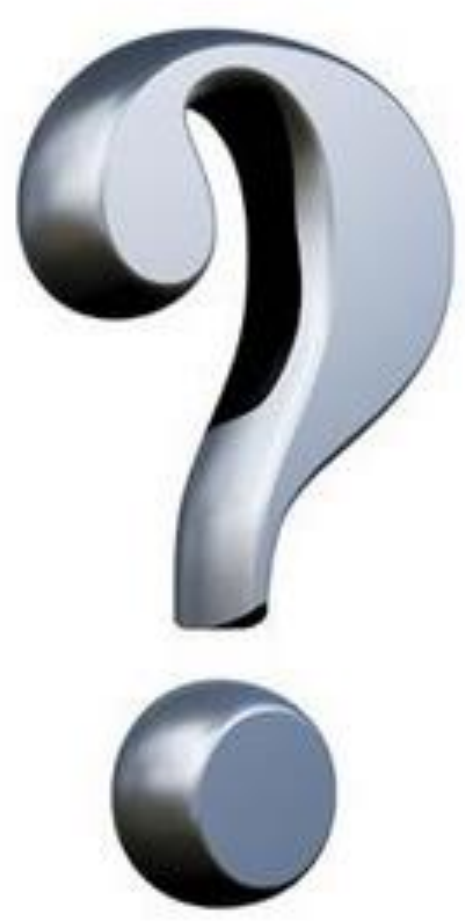

Email: Trenton.M.Ricks@nasa.gov 


\section{Prior Study Results related to Thermally Induced Stresses in TBC-Protected Plate}

- Effect of geometry on free-edge interlaminar stresses: no effect of $L / H$, significant effect of $t_{B C} / H$

- Effect of bond coat properties on free-edge interlaminar stresses: significant effect of $\alpha_{B C}$ and $E_{B C}$, small effect of $\kappa_{B C}$

- Effect of top coat properties on free-edge interlaminar stresses: smaller effect of $\alpha_{\mathrm{TC}}$ and $\mathrm{E}_{\mathrm{TC}}$ relative to $\alpha_{\mathrm{BC}}$ and $\mathrm{E}_{\mathrm{BC}}$

- Effect of substrate properties on free-edge interlaminar stresses: relatively small effect of $\alpha_{S}$ and $E_{S}$ along TC/BC interface, with substantially greater effect along $\mathrm{BC} / \mathrm{S}$ interface

- Effect of through-thickness thermal gradient on free-edge interlaminar stresses: the magnitude of the gradient has significant effect

- Change in sign of the peel stress with increasing gradient from tension to compression

* "Thermally-Induced Interlaminar stresses in TBC-Protected Plate: A Material and Geometric

Parametric Study"; Arnold et al., HITEMP Review 1995, Vol. II, CP 10178, pp. 34:1-14 


\section{Modeling Philosophy: Trade Offs}
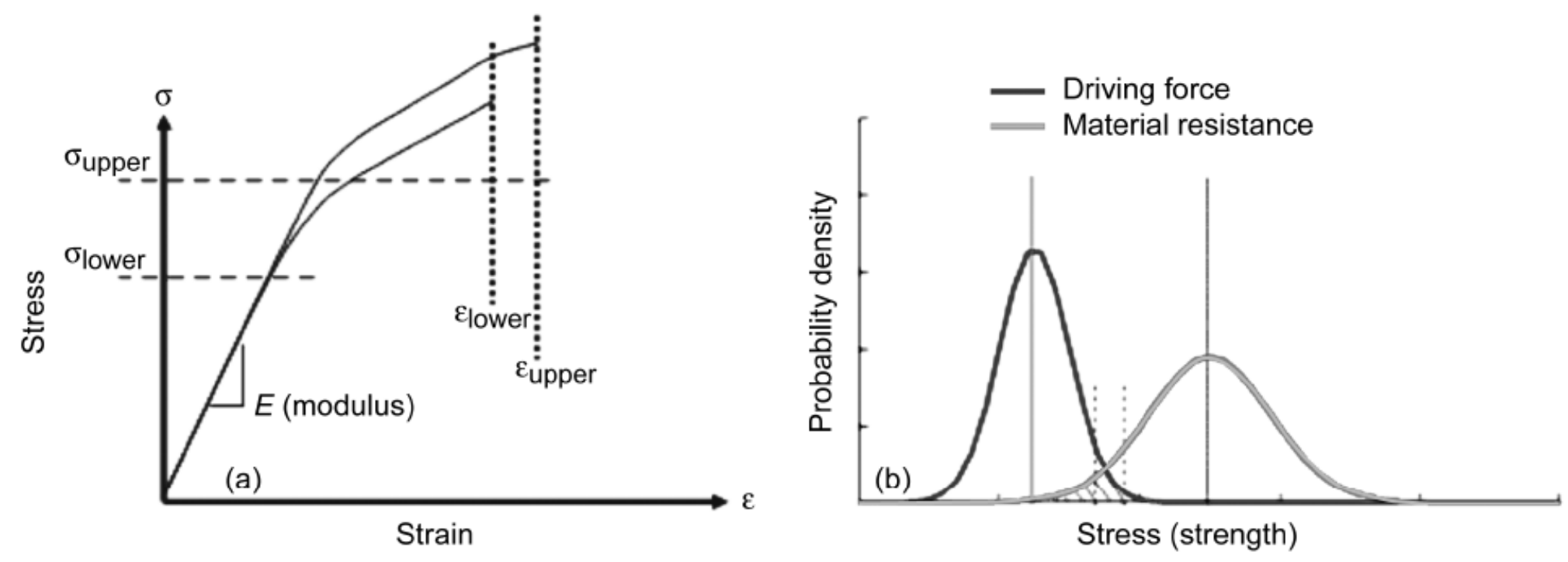

Actuality both driving force (applied loads and local architecture) and material resistance (dependent upon both local architecture and processing methodology) are spatially varying throughout a given component/specimen.

1) Assume a fixed (pristine) architecture (Driving Forces) with specific architectural parameters that can be varied (e.g., tow spacing, tow shape, etc.) to obtain a statistical distribution of resulting stresses. These stresses then can be compared with statically and spatially varying material strength values (Resistance).

2) Alternatively, one can analyze local architecture (e.g., ply shifting, ply rotation, nesting, etc.) and the flaw and porosity distribution in great detail using high-fidelity numerical analyses to obtain detailed local stresses (i.e., driving forces). These stresses can be compared with a fixed value of material strength (resistance). 